\title{
SEISMIC OPTIMIZATION ANALYSIS OF VERTICAL STIFFENER CONNECTION TO L-CFST COLUMN
}

\author{
Wang Zhang 2, 5, Zhi-Hua Chen ${ }^{1,2,3}$, Qing-Qing Xiong ${ }^{2,5}$ and Ting Zhou ${ }^{4, *}$ \\ 'State Key Laboratory of Hydraulic Engineering Simulation and Safety, Tianjin, China \\ ${ }^{2}$ Department of Civil Engineering, Tianjin University, Tianjin, China \\ ${ }^{3}$ Key Laboratory of Coast Civil Structure Safety of China Ministry of Education, Tianjin University, China \\ ${ }^{4}$ Department of Architecture, Tianjin University, Tianjin, China \\ ${ }^{5}$ School of Civil Engineering, Shijiazhuang Tiedao University, Shijiazhuang, China \\ * (Corresponding author: E-mail: zhouting1126@126.com)
}

\section{A B S T RA C T}

In this paper, 14 models in two series were designed and numerically analysed based on the results of quasi-static tests of vertical stiffener connections to L-CFST columns. For the fracture problem of the beam flange connecting plate at the end of the vertical stiffener, four optimization methods were proposed and compared in the H300 series: tapered vertical stiffener, flush vertical stiffener with beam flange, reduction beam section and thickened beam flange connecting plate. For the problem of the vertical stiffener fracture along the column flange, the effect of the vertical stiffener sectional area and width-to-thickness ratio were considered and analysed in the H400 series. The skeleton curves, Von Mises stress distribution and fracture index of each model in the two series were compared. The crack propagation on the beam flan ge connecting plate and vertical stiffener can be reduced and even eliminated using a thickened connecting plate and a minor width-to-thickness ratio, respectively. A calculation method for the flexural capacity of the vertical stiffener connection to the L-CFST column was proposed. Good consistency was observed between the theoretical and test results of both yield and ultimate flexural capacity. Finally, a design example of the flexural capacity of the connection is provided to guide the engineering practice.

\section{A R T I C LE H I S T O RY}

$\begin{array}{ll}\text { Received: } & 9 \text { August } 2017 \\ \text { Revised: } & \text { 4 March 2018 } \\ \text { Accepted: } & \text { 1 April 2018 }\end{array}$

\section{K E Y W O R D S}

L-shaped column composed of concrete-filled steel tubes; vertical stiffener connection; optimization analysis; crack;

flexural capacity

\section{Introduction}

The special-shaped column frame system has attracted increasing attention in the residential construction industry because of its advantages such as the prominent absence of columns, large usable space in buildings and convenience of furniture layouts. Because of the weak seismic behaviour of the frame structure system with the special-shaped reinforced concrete column, the height of this structure system has strict limitations in earthquake-prone areas [1]. Meanwhile, the concrete-filled steel tubular column has been studied by many scholars because of its beneficial seismic behaviour, high bearing capacity, fireproofing qualities and economic benefits [2-7]. The research background of this paper is the frame structure system of a special-shaped column composed of concrete-filled steel tubes (S-CFST column), which can be applied to high-rise steel residential buildings particularly with braces or shear walls. Specialshaped columns composed of concrete-filled steel tubes are divided into L-, Tand cross-shapes and can be wrapped inside the wall, as shown in Fig. 1. However, in engineering designs, L-shaped columns composed of concrete-filled steel tubes (L-CFST columns) are the ideal member forms for economic reasons $[8,9]$ because the stiffness and strength of L-CFST columns can be increased by extending the length or increasing the thickness of the boundary mono columns or vertical steel plates. The L-CFST column with vertical stiffener connections is shown in Fig. 2.

At present, scholars have paid more attention to the seismic behaviour of different connections to concrete-filled rectangular steel tubular columns and their flexural and shear capacity calculation methods. These connections include external-diaphragm connections [10], through-diaphragm connections [11], internal-diaphragm connections [12-14] and vertical stiffener connections [15-18]. However, there are relatively few experimental and theoretical studies of the special-shaped column frame joints. The seismic performance of L-, Tand cross-shaped steel-tube columns with internal-diaphragms was studied by Xue et al. [19]. However, the internal diaphragm is not conducive to welding construction in connection regions and concrete pouring in steel tubes, particularly for small-size steel-tube sections in residential buildings. Xu et al. [20] experimentally studied the external diaphragm connections between $\mathrm{T}$ - and cross-shaped columns with steel beams. However, this type of connection requires more steel and affects the living space and aesthetics. Ma et al. [21] conducted cyclic loading tests of two full-scale flange-reinforced connection specimens, which are similar to the vertical stiffener connection in this paper. The test result showed that the cracking of the steel beam flanges in two specimens occurred at the end of the reinforcement, and the deformation of the panel zone was not obvious.
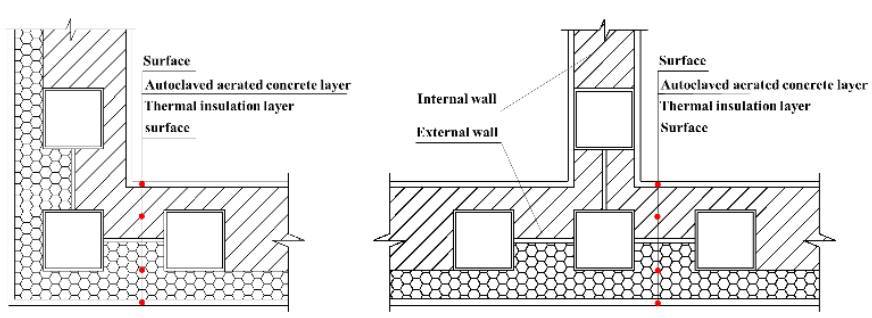

(a) L-CFST column as a corner joint

(b) T-CFST column as an exterior joint

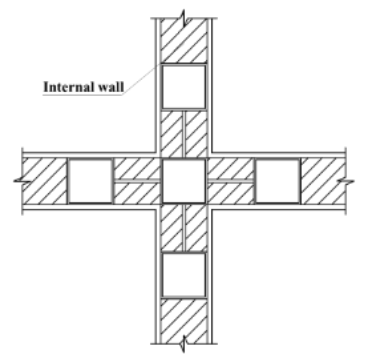

(c) Cross-CFST as an interior joint

Fig. 1 Layout of S-columns with different sections

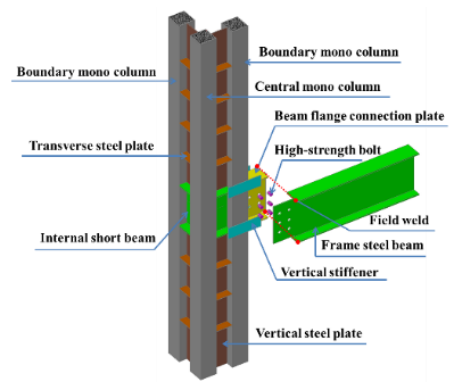

Fig. 2 Installation diagram of the vertical stiffener connection between an L-CFST column and a frame steel beam 
To study the seismic behaviour of the vertical stiffener connection to the LCFST column, the presence of concrete, width-to-thickness ratio of the vertical stiffener, internal extending length of the vertical stiffener, and section area of the vertical stiffener were analysed in five specimens [8]. The dimension details of Specimen H300-2 are shown in Fig. 3, and the other specimens were adjusted only in the local component size, as shown in Table 1.

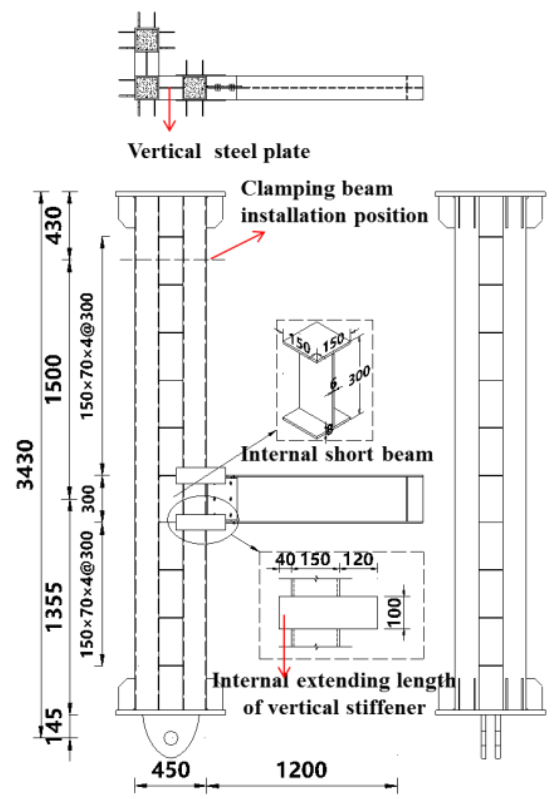

Fig. 3 Details of Specimen H300-2

Table 1

Summary of the test specimens

\begin{tabular}{cccc}
\hline $\begin{array}{c}\text { Specimen } \\
\text { No. }\end{array}$ & $\begin{array}{c}B \times t \\
(\mathrm{~mm})\end{array}$ & Concrete & $\begin{array}{c}\text { Internal extending length of vertical } \\
\text { stiffener }(\mathrm{mm})\end{array}$ \\
\hline H300-0 & $100 \times 6$ & Filled & 0 \\
H300-1 & $75 \times 8$ & Filled & 0 \\
H300-2 & $100 \times 6$ & Hollow & 40 \\
H400-0 & $100 \times 6$ & Filled & 40 \\
H400-1 & $100 \times 12$ & Filled & 40 \\
\hline
\end{tabular}

Specimens H300-0, H300-1 and H300-2 had similar failure process and final damage results. Only minor cracks were generated at the beam flange connecting plate at the end of the vertical stiffener when the loading at the end of the steel beam was small. With the increase in loading, the crack length of the upper and lower flange connecting plates in the diagonal position quickly increased. Finally, the cracks extended to the shear plate, and the steel beam developed serious torsion. There was a slight heave at the column flange, and the deformation and cracks in the panel zone of the joint were not observed.

When the force increased at the steel beam end, the upper south and lower north vertical stiffeners in Specimen H400-0 were broken. Then, the displacement of the beam end rapidly increased, whereas the bearing capacity decreased sharply. However, the failure began with the weld cracking between the vertical stiffeners and the beam flange connecting plate in Specimen H400-1. In the loading process, continuous distinctive sounds emitted from it, and the weld between the vertical stiffener and the beam flange connecting plate completely cracked. Then, the column flange cracked. After the test, the weld of the internal extending part of the vertical stiffener cracked, and dislocation also occurred between the vertical stiffeners and internal short beam flange.

Considering the unreasonable phenomenon in the test, 14 analytic models in two series with different configurations were designed and optimized by the finite-element method to improve the seismic performance. By analysing the bearing capacity of the analytic models, Von Mises stress distribution and rupture index, this paper provides the experimental support and design basis to apply and generalize this structural system.

\section{Model parameters and result verification of FEM}

\subsection{Model parameters}

Since the centroid and shear centre of L-CFST columns do not coincide,

under the seismic action, L-CFST columns easily twist around the shear centre of the cross section, as shown in Fig. 4, which aggravates the cracking of the beam flange connecting plate at the end of the vertical stiffener. Simultaneously, the rupture risk of the vertical stiffener at the column flange increases under the dual action of the tension of the steel beam flange and cross-sectional shear moment around the L-CFST column. Existing quasi-static test results on the Tshaped stiffener-steel beam connection show that the rupture of the steel beam flange at the end of the vertical stiffener is the root cause of the poor performance of many test specimens in terms of plasticity and bearing capacity $[16,21-22]$. Thus, some scholars have investigated the cracking of the steel beam flange caused by reinforcement at both sides of the column flange [23].

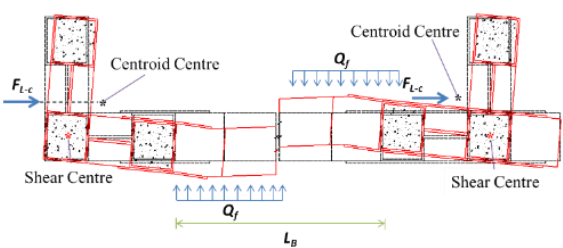

Fig. 4 Plane deformation and force diagram of the L-CFST column framework

In this section, 14 analytic models in two series (H300 and H400) were designed for the rupture of the beam flange connecting plate in the test with the 300 -mm-high beam and the rupture of the vertical stiffener in the test with the 400-mm-high beam.

In the H300 series, Specimen H300-0 was used as the basic contrast model. The tapered vertical stiffener model (H300-T), flush vertical stiffener with the beam flange model (H300-F), reduction beam section model (H300-RBSD20 and H300-RBSD40) and models (H300-BFCPT10 and H300-BFCPT12) with the thickness of the beam flange connecting plate increasing by $2 \mathrm{~mm}$ and $4 \mathrm{~mm}$ were used for the optimization analysis. The specific naming and detailed parameters are shown in Fig. 5 and Fig. 6.

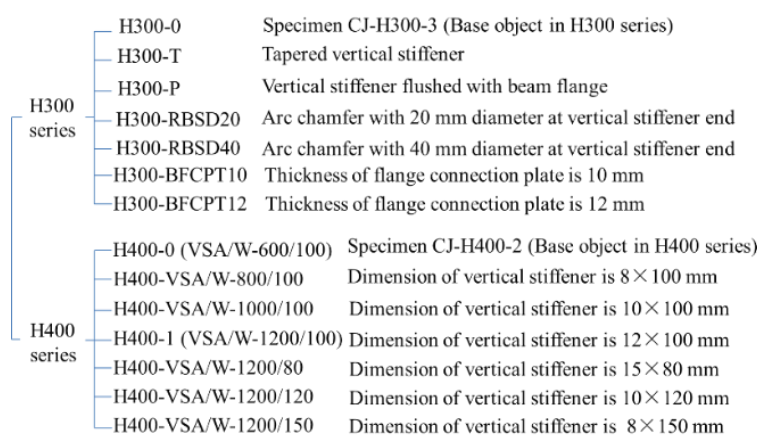

Fig. 5 Specific naming convention of all analytic models

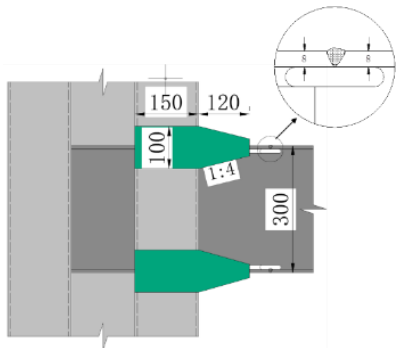

(a) H300-T

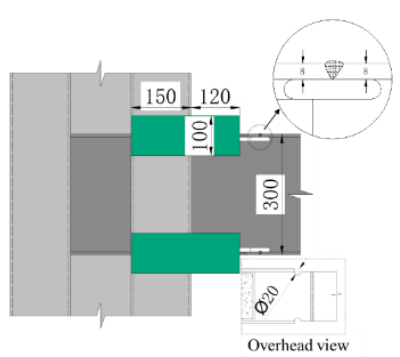

(c) H300-RBSD20

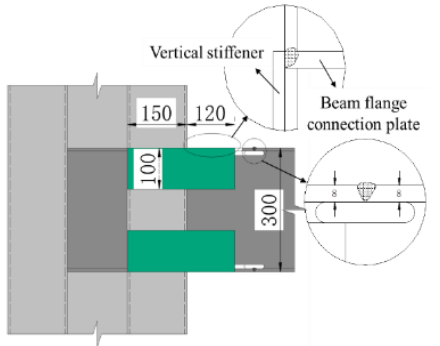

(b) H300-F

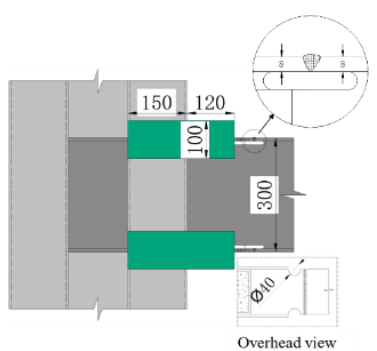

(d) H300-RBSD40 


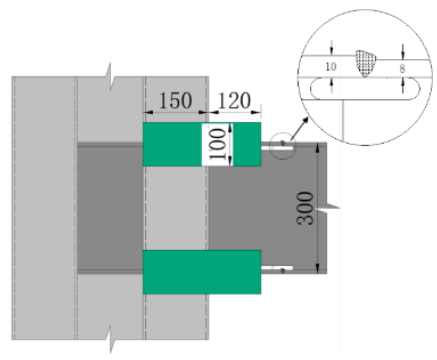

(e) H300-BFCPT10

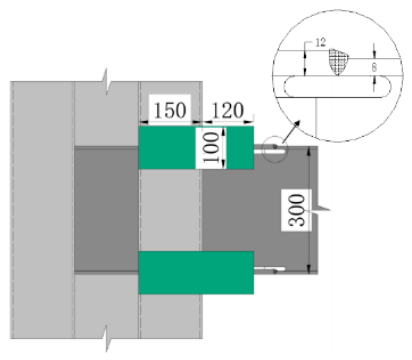

(f) $\mathrm{H} 300-\mathrm{BFCPT} 12$
Fig. 6 Detailed parameters of the analytic models in the H300 series

In the $\mathrm{H} 400$ series, specimens $\mathrm{H} 400-0$ and $\mathrm{H} 400-1$ are the basic contrast models, and the sectional area and width-to-thickness ratio of the vertical stiffener were the research objects to design 5 parameterized analytic models: H400-VSA/W-800-100, H400-VSA/W-1000-100, H400-VSA/W-1200-80, H400-VSA/W-1200-120 and H400-VSA/W-1200-150. The seismic performances of the analytic models H400-VSA/W-600-100 (H400-0), H400VSA/W-800-100, H400-VSA/W-1000-100 and H400-VSA/W-1200-100 (H400-1) were compared when all vertical stiffeners were $100 \mathrm{~mm}$ wide and the areas were $600 \mathrm{~mm}^{2}, 800 \mathrm{~mm}^{2}, 1000 \mathrm{~mm}^{2}$ and $1200 \mathrm{~mm}^{2}$, respectively. The seismic performances of the analytic models H400-VSA/W-1200-80, H400VSA/W-1200-100 (H400-1), H400-VSA/W-1200-120, and H400-VSA/W1200-150 were compared when the areas of all vertical stiffeners were 1200 $\mathrm{mm}^{2}$ and the widths were $80 \mathrm{~mm}, 120 \mathrm{~mm}, 120 \mathrm{~mm}$ and $150 \mathrm{~mm}$, respectively. The specific naming convention is shown in Fig. 5.

\subsection{Finite element modelling}

The models were analysed using the general finite-element software ANSYS. The concrete filled in the mono column was modelled by element Solid65. The vertical steel plate and transverse steel plate were modelled by element Shell191. Other steels were modelled by element Solid95. The contact element pair Targe 170 and Conta 174 was applied at the contact surfaces. The friction coefficients were equal to $0.4,0.1$ and 0.4 between connecting stiffener and beam web, between bolt shank and bolt hole, and between steel tube and concrete, respectively.

Three reference points were established at the plane centroid point of the top and bottom of the L-CFST column for constraining and the cross-sectional centroid point of the steel beam end for loading. The specific boundary conditions of the models are shown in Fig. 7.

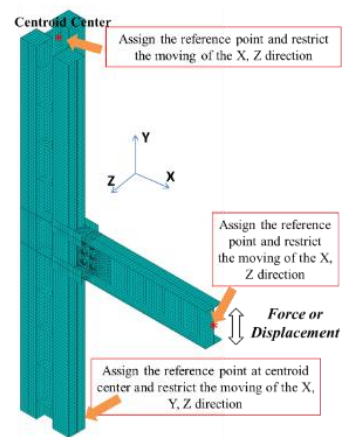

Fig. 7 Typical meshing, boundary condition and loading on the models

\subsection{Results verification of FEM}

The finite-element results of Specimen H300-0 are shown in Fig. 8. Since the effect of the welding residual stress of the specimen and the gradual cracking of the steel beam flange at the end of the vertical stiffener were not considered, the peak bearing capacity obtained by the finite-element model was $152.6 \mathrm{kN}$, which is approximately $19.7 \%$ higher than the test value of $127.4 \mathrm{kN}$. This result occurred because the beam flange connecting plate gradually cracked at the end of the vertical stiffener in the loading process, which decreased the tension cross-section of the steel beam flange and made the bearing capacity fail to reach the theoretical value. Because of the crack of the beam flange connecting plate, the bearing capacity could not be given full play. Fig. 8 (d) shows that the stress of the lower steel beam flange on the place at a distance from the end of the vertical stiffener was large, and the steel beam flange bent. In Fig. 8 (e), the strain at the junction area of the vertical stiffener and beam flange connecting plate was large, and the maximum Von Mises strain of 0.385 occurred on the beam flange connecting plate at the end of the vertical stiffener, which was 208 times higher than the yield strain of the beam flange connecting plate.

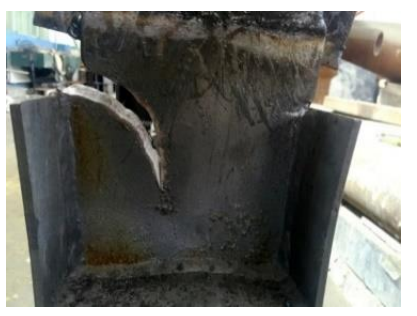

(a) Flange fracture

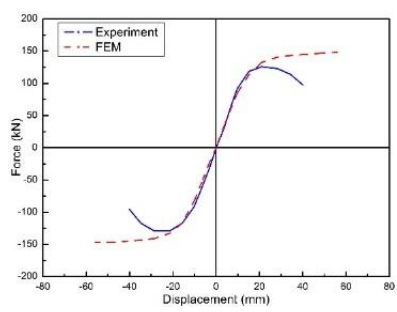

(c) Comparison of skeleton curves of experiment and FEM

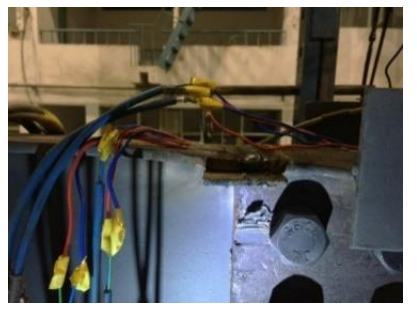

(b) Flange buckling

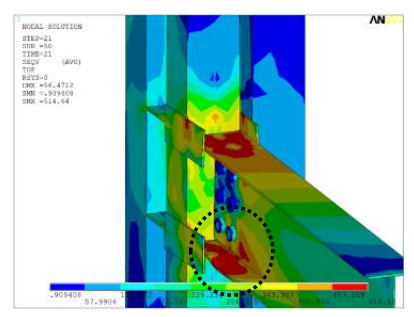

(d) Von Mises stress

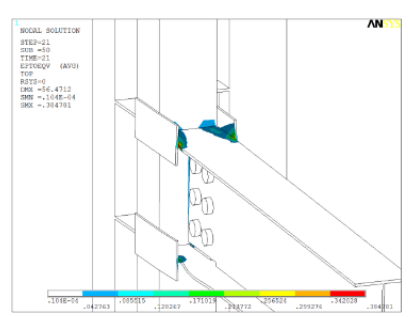

(e) Von Mises strain

Fig. 8 Comparison of the finite-element analysis results with the experimental results

The finite-element analysis of Specimen H400-0 is shown in Fig. 9. Since the sudden rupture of the vertical stiffener was not considered in the finiteelement model, the finite element obtained a skeleton curve with superior ductility compared to the test. Simultaneously, the forces of the test and finiteelement method (FEM) at the peak loading point were $318.4 \mathrm{kN}$ and $329.5 \mathrm{kN}$, respectively. The error was approximately $3.5 \%$. In Fig. 9 (c), Von Mises value of the connection was maximal at the junction of the column flange and vertical stiffener. The stress at the junction of the vertical stiffener and beam flange connecting plate was also large. In Fig. 9 (d), the maximum Von Mises strain was on the vertical stiffener and distributed along the column flange, which is notably consistent with the rupture phenomenon of the vertical stiffener in the testing process.

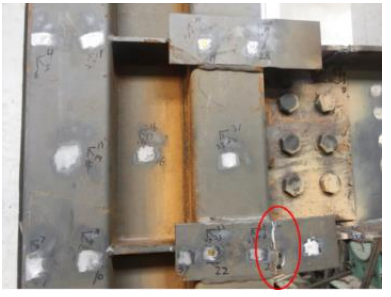

(a) Vertical stiffener fracture

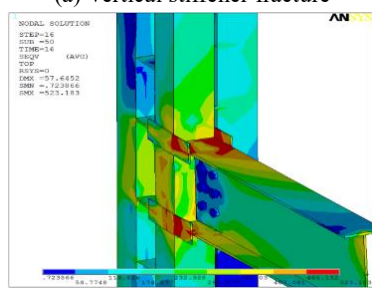

(c) Von Mises stress

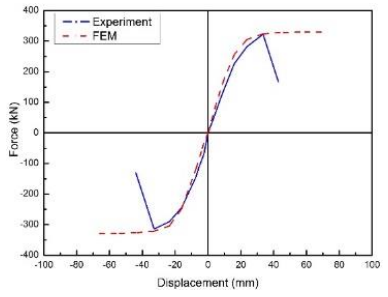

(b) Comparison of skeleton curves

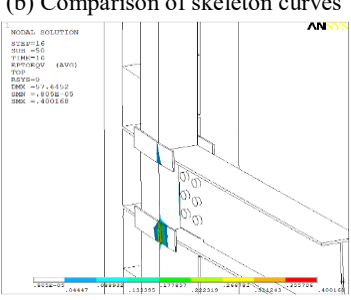

(d) Von Mises strain
Fig.9 Numerical results of Specimen H400-0 
The analysis results illustrate the feasibility of predicting the seismic performance of the analytic models in the H300 series and H400 series using the finite-element method.

\section{Seismic performance analysis}

\subsection{Skeleton curves}

The skeleton curves of 7 analytic models in the H300 series are shown in Fig. 10 (a). According to the Fig., except for H300-BFCPT10 and H300BFCPT12, the bearing capacities of all other analytic models decreased compared to $\mathrm{H} 300-0$, where the bearing capacity of the analytic model $\mathrm{H} 300-\mathrm{T}$ reduced by approximately $0.8 \%$, which indicates that the effect of the vertical stiffener form on the decrease in bearing capacity is negligible. The bearing capacity of model $\mathrm{H} 300-\mathrm{F}$ decreased by $11 \%$ because the decrease in effective tensile area of the vertical stiffener blocked the full performance of its bearing capacity. The bearing capacity of this construction form can be increased by welding the cover plates on the upper and lower beam flanges [23]. The bearing capacities of models H300-RBSD20 and H300-RBSD40 decreased by $7.7 \%$ and $12.2 \%$, respectively. In the high-rise steel structure housing system in the paper, because of the restriction on the width of the steel beam flange, using this type of structure will sacrifice considerable bearing capacity of the connection. For analytic models H300-BFCPT10 and H300-BFCPT12 with beam flange connecting plates thickened by $2 \mathrm{~mm}$ and $4 \mathrm{~mm}$, respectively, all bearing capacities increased by $15 \%$; hence, increasing the thickness of the beam flange connecting plate can significantly increase the bearing capacity of the connection in a certain range. However, the force rapidly decreased when analytic model $\mathrm{H} 300$-BFCPT12 reached the peak force, which indicates that the ductility decreases when the thickness of the beam flange connecting plate significantly increases.

The skeleton curves of 7 analytic models in H400 series are shown in Fig. 10 (b). After a comparison among the analytic models H400-VSA/W-600/100, H400-VSA/W-800/100, H400-VSA/W-1000/100 and H400-VSA/W$1000 / 120$, with the increase in area of the vertical stiffener to $800 \mathrm{~mm}^{2}$, the bearing capacity of the connection no longer increased. Simultaneously, after comparing H400-VSA/W-1200/80, H400-VSA/W-1200/100, H400-VSA/W$1200 / 120$ and H400-VSA/W-1200/150, if the area of the vertical stiffener is unchangeable, with the decrease in width-to-thickness ratio of the vertical stiffener, the bearing capacity of the connection slightly reduced but only by $1.2 \%$ compared between H400-VSA/W-1200/80 and H400-VSA/W-1200/150. Thus, the width-to-thickness ratio of the vertical stiffener hardly affects the bearing capacity of the connection. Because a large width-to-thickness ratio will cause the corner exposure of the stiffener and affect the indoor aesthetics of the high-rise steel structure house, a small width-to-thickness ratio should be used, if possible.

Table 2

Comparison of the bearing capacity of analytic models in the H300 and H400 series

\begin{tabular}{cccc}
\hline Series & Analytic model No. & $\begin{array}{c}\text { Average bear ca- } \\
\text { pacity }(\mathrm{kN})\end{array}$ & Error (\%) \\
\hline \multirow{4}{*}{ H300 } & H300-T & 152.6 & - \\
& H300-F & 152.0 & -0.8 \\
& H300-RBSD20 & 136.0 & -11.0 \\
& H300-RBSD40 & 140.8 & -7.7 \\
& H300-BFCPT10 & 134.0 & -12.2 \\
& H300-BFCPT12 & 175.5 & 15.0 \\
& H400-0 & 311.3 & 15.0 \\
\hline H400-VSA/W-800/100 & 370.3 & 19.0 \\
& H400-VSA/W-1000/100 & 370.5 & 19.0 \\
& H400-VSA/W-1200/100 & 369.0 & 18.5 \\
& H400-VSA/W-1200/80 & 367.7 & 18.1 \\
& H400-VSA/W1200/120 & 369.5 & 18.7 \\
& H400-VSA/W-1200/150 & 372.2 & 19.6 \\
\hline
\end{tabular}

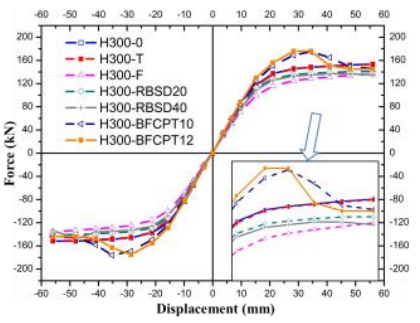

(a) H300 series

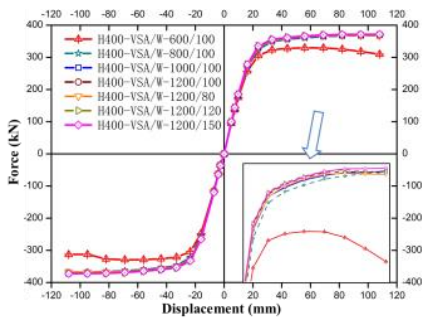

(b) $\mathrm{H} 400$ series
Fig. 10 Skeleton curves of the analytic models

\subsection{Von mises stress distribution}

Von Mises stress distributions of the analytic models in the $\mathrm{H} 300$ series with the beam end displacement of $56.6 \mathrm{~mm}$ are shown in Fig. 11. For analytic model $\mathrm{H} 300-\mathrm{T}$, the stress in the beam flange connecting plate region in the vertical stiffener was large and evenly distributed. The beam flange did not obviously bend. The beam flange connecting plate region had a notably different stress distribution from the basic analytic model H300-0 (as shown in Fig. 8 (d)). Hence, the tapered vertical stiffener promoted the bearing capacity of the beam flange connecting plate to give full play. For analytic model H300$\mathrm{F}$, near the column flange, the stress in the middle of the beam flange connecting plate was small; however, the stresses at both ends were large, so the vertical stiffener had little contribution to the bearing capacity of the connection in this form of construction. On the vertical stiffener, it was easy to form a large stress concentration at the beam flange connecting plate and the column flange, which was adverse to the seismic performance of the connection. The stress distribution of the vertical stiffener end chamfering of analytic models H300RBSD20 and H300-RBSD40 shows that the stress in the beam flange connecting plate region in the vertical stiffener was evenly distributed, and the local bending formed at the arc chamfer and extended to the column flange. For this type of structure, since the arc chamfer was at the end of the vertical stiffener and near the column flange, the local bending of the beam flange can easily destroy the panel zone. For this type of construction, the extended part of the vertical stiffener should be appropriately lengthened to protect the panel zone. For analytic models H300-BFCPT10 and H300-BFCPT12, the stress in the area inside the vertical stiffener gradually reduced with the increase in thickness of the beam flange connecting plate, but an obvious plastic hinge formed on the steel beam flange. Thus, this type of construction can well protect the panel zone and form an energy dissipation section, which was conductive to the seismic performance of the connection.

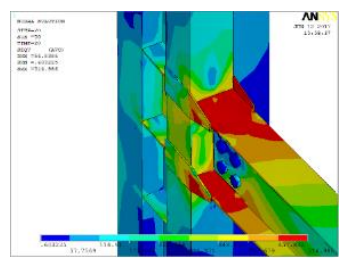

(a) $\mathrm{H} 300-\mathrm{T}$

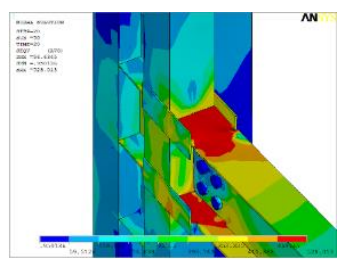

(c) H300-RBSD20

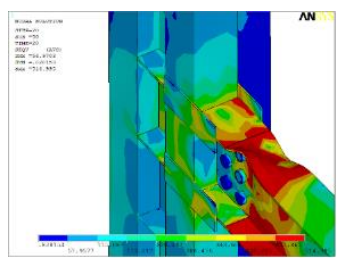

(e) H300-BFCPT10

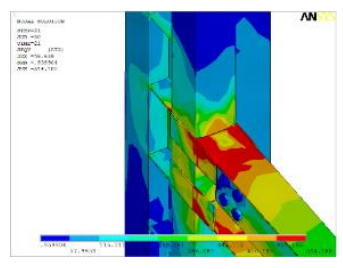

(b) H300-F

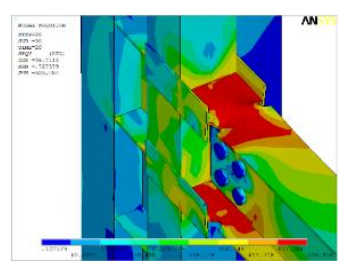

(d) H300-RBSD40

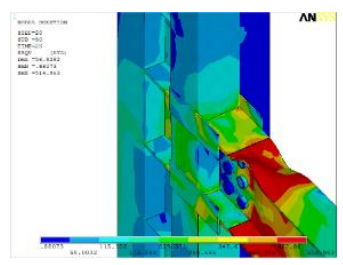

(f) H300-BFCPT12
Fig 11 Von Mises stress of analytic models in the H300 series 
with the beam end displacement of $110 \mathrm{~mm}$ are shown in Fig. 12. According to Figs. 12 (a), (b) and (c), with the increase in area of the vertical stiffener, the bending degree of the steel beam at the end of the stiffener increased. However, when the area of the vertical stiffener was $1000 \mathrm{~mm}^{2}$, its bending degree of the steel beam flange no longer changed. According to Figs. 12 (c), (d), (e) and (f), when the area of the vertical stiffener was fixed $\left(1200 \mathrm{~mm}^{2}\right)$, with the increase in width-to -thickness ratio of the vertical stiffener, the bending degree of the steel beam flange slightly changed, but the maximum Von Mises stress was narrowly distributed through the entire cross section of the lower vertical stiffener under the tension. This analysis explains that the flexural capacity of the vertical stiffener connection to L-CFST column was directly related to the area of the vertical stiffener but barely affected by its width-to-thickness ratio.

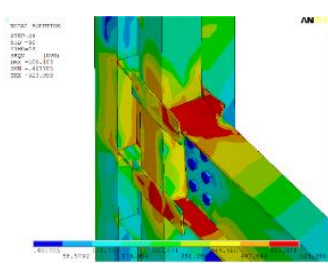

(a) H400-VSA/W-800/100

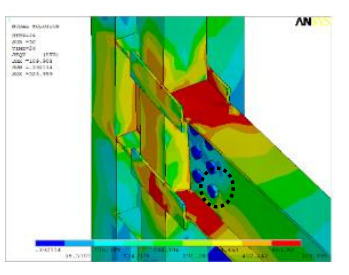

(c) H400-VSA/W-1200/100

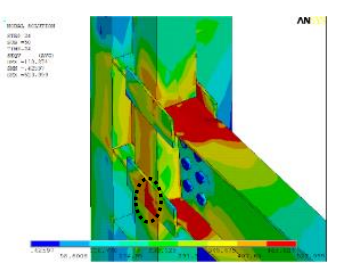

(e) H400-VSA/W-1200/120

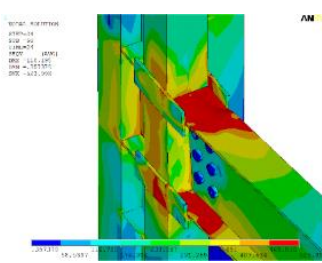

(b) H400-VSA/W-1000/100

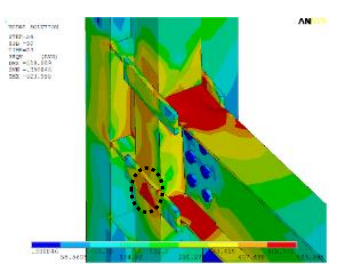

(d) H400-VSA/W-1200/80

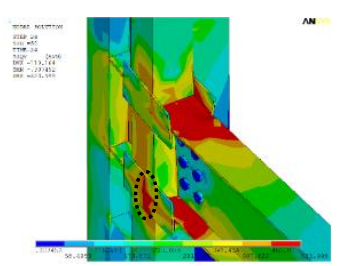

(f) H400-VSA/W-1200/150
Fig. 12 Von Mises stress of analytic models in the H400 series

\subsection{Rupture evolution analysis}

The rupture index was introduced by Hancock and Mackenzie [24] for the equivalent plastic rupture strain of steel for different stress triaxiality conditions. To compare the rupture degrees of the connections in different forms of improvement at the beam flange connecting plate at the end of the vertical stiffener, the method was used in this paper to assess the rupture risk. It has been used by many scholars, and its correctness has been verified [23-27]. The rupture index (RI) is expressed in Eq. (1). A greater RI indicates higher rupture risk.

$$
R I=\frac{\varepsilon_{e p v}^{p l} / \varepsilon_{y}}{\exp \left(-1.5 \frac{\sigma_{m}}{\sigma_{e f f}}\right)}
$$

where $\varepsilon_{\mathrm{p}}, \varepsilon_{\mathrm{y}}, \sigma_{\mathrm{m}}$, and $\sigma_{\text {eff }}$ are the equivalent plastic strain, yield strain, hydrostatic stress, and Von Mises stress, respectively.

The ratio of the hydrostatic stress to the Von-Mises stress (i.e., $\sigma_{\mathrm{m}} / \sigma_{\mathrm{eff}}$ ), which appears in the denominator of Eq. (1), is called the Triaxiality Ratio (TR), as shown in Eq. (2). El-Tawil et al. [28] reported that TR values less than -1.5 could cause brittle fracture, whereas values between -0.75 and -1.5 usually resulted in a large decrease in rupture strain of the metal.

$$
T R=\frac{\sigma_{m}}{\sigma_{e f f}}
$$

The ratio of the equivalent plastic strain to the yield strain in the numerator of Eq. (1) is called the plastic equivalent strain (PEEQ) index. The PEEQ is a measure of the local inelastic strain demands, which can be useful in evaluating and comparing the performance of different connection configurations. The PEEQ index is computed by Eq. (3),
$P E E Q=\frac{\varepsilon_{\mathrm{eqv}}^{\mathrm{pl}}}{\varepsilon_{\mathrm{y}}}=\frac{\int \sqrt{\frac{2}{3} d \varepsilon_{\mathrm{ij}}^{\mathrm{p}} d \varepsilon_{\mathrm{ji}}^{\mathrm{p}}}}{\varepsilon_{\mathrm{y}}}$

where is the plastic strain rate tensor components in directions $\mathrm{i}$, and $\mathrm{j}$; $\varepsilon_{\mathrm{y}}$ is the yield strain of the beam flange connecting plate.

For the analytic models in the $\mathrm{H} 300$ series, the rupture critical points a and $\mathrm{b}$ of the beam flange connecting plate at the end of the vertical stiffener along the width direction were determined (as shown in Fig. 13 (a)). The obtained values of the PEEQ index, triaxiality index and rupture index are plotted along the beam flange at the peak force state in Fig. 14. In addition, TR, PEEQ and RI of the analytic models at critical points $\mathrm{a}$ and $\mathrm{b}$ are listed in Table 3.

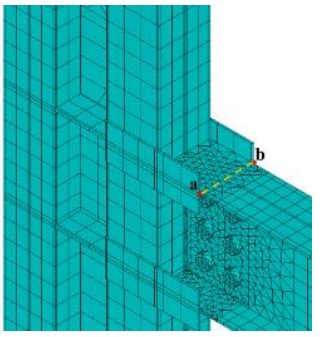

(a) $\mathrm{H} 300$ series

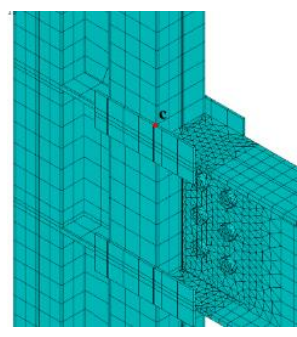

(b) H400 series
Fig. 13 Analytic models of the two series and their critical points

Fig. 14 shows that at the peak force state, TR, PEEQ and RI of the analytic models significantly varied with the range of $15 \mathrm{~mm}$ from either side of the beam flange connecting plate to the end of the vertical stiffener, but those values were basically similar at other positions. Thus, different optimization measures have remarkable effect on the rupture of the beam flange connecting plate at the end of the vertical stiffener.

Fig. 14 (a) and Table 3 show that the analytic models with improvement at the critical points had larger TR indices (above -0.8) than the basic model H3000 . The reduction beam section models H300-RBSD20 and H300-RBSD40 had the smallest TR values, which were above -0.4 . Hence, those improvement measures might have certain effects on improving the brittle rupture of the beam flange connecting plate.

The equivalent plastic strain index diagram indicates the plastic strain demand at the critical points; therefore, an increase in this parameter can indicate an increase in probability of rupture at the mentioned points. From Fig. 14 and Table 3, except for the analytic model H300-BFCPT12 at the critical points, which had the minimal value, all PEEQ values of other models exceeded 120. In addition, the PEEQ values of the analytic models H300-RBSD20, H300$\mathrm{T}$ and $\mathrm{H} 300-0$ were larger than 596.9 at the critical points, and those of the basic model H300-0 were greater than 1000. In addition, the PEEQ values of the analytic models H300-RBSD20 and H300-RBSD40 with the arc chamfering at the end of the vertical stiffener showed an increasing trend. Thus, the improvement measure can reduce the equivalent plastic strain of the beam flange connecting plate at the critical point, but the presence of the arc chamfering increases the equivalent plastic strain in the middle of the beam flange connecting plate.

According to Fig. 14(c), the RI values of the analytic models significantly differed at the critical points. The analytic model H300-RBSD20 had an RI value above 388.4 , but H300-BFCPT12 had the minimum RI of 18.6. The RI values of the other analytical models were 2.6-23 times larger than that of $\mathrm{H} 300$ BFCPT12. Thus, the analytic model with the beam flange connecting plate thickened by $4 \mathrm{~mm}$ most significantly decreases the brittle rupture of the steel beam flange at the end of the vertical stiffener. In addition, in Table 3, the RI value at the critical point a was larger than that of $b$, which indicates that the twist of the L-CFST column exacerbated the rupture of the beam flange connecting plate at the end of the vertical stiffener.

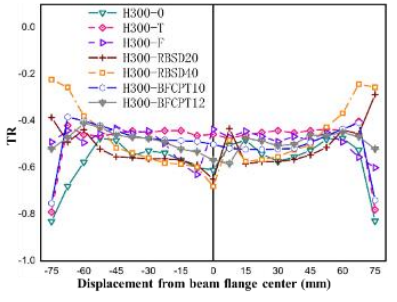

(a)

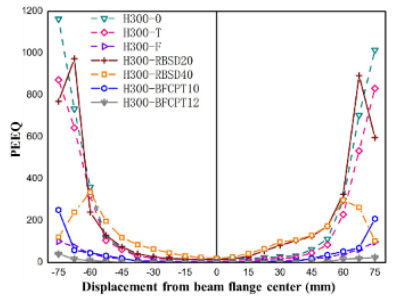

(b) 


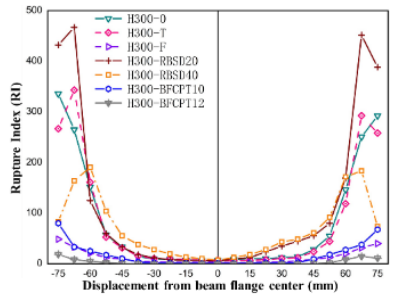

(c)

Fig. 14 TR, PEEQ, and RI along the beam flange connecting plate at peak force state in the $\mathrm{H} 300$ series

Table 3

TR, PEEQ and RI of the beam flange connecting plate at the end of vertical stiffeners in the H300 series

\begin{tabular}{|c|c|c|c|c|c|c|}
\hline \multirow{2}{*}{ Analytic model } & \multicolumn{2}{|c|}{ TR } & \multicolumn{2}{|c|}{ PEEQ } & \multicolumn{2}{|c|}{ RI } \\
\hline & Point a & Point $b$ & Point a & Point $b$ & Point a & Point $b$ \\
\hline $\mathrm{H} 300-0$ & -0.83 & -0.83 & 1163.2 & 1015.3 & 335.9 & 292.3 \\
\hline $\mathrm{H} 300-\mathrm{T}$ & -0.79 & -0.78 & 872.7 & 832.2 & 266.8 & 258.3 \\
\hline H300-P & -0.49 & -0.6 & 100.8 & 98.0 & 48.6 & 40.0 \\
\hline H300-RBSD20 & -0.39 & -0.29 & 770.1 & 596.9 & 432.2 & 388.4 \\
\hline H300-RBSD40 & -0.26 & -0.22 & 121.7 & 102.6 & 83.0 & 73.5 \\
\hline Н300-ВFCPT 10 & -0.76 & -0.75 & 251.2 & 208.8 & 80.0 & 67.5 \\
\hline Н300-ВFCРТ 12 & -0.52 & -0.51 & 40.54 & 24.05 & 18.6 & 11.04 \\
\hline
\end{tabular}

For the H400 series, this paper studies the changes in TR, PEEQ and RI of the vertical stiffeners at the vertical stiffener at critical point $\mathrm{c}$ with the beam end displacement. Fig. 15 presents the change trend of the analytic models at critical point $\mathrm{c}$ for different unilateral vertical stiffener areas $\left(600 \mathrm{~mm}^{2}, 800 \mathrm{~mm}^{2}\right.$, $1000 \mathrm{~mm}^{2}$ and $1200 \mathrm{~mm}^{2}$ ). According to the Fig., with the increase in vertical stiffener area, the absolute values of TR, PEEQ and RI at critical point $\mathrm{c}$ decreased sharply, which indicates that the brittle rupture of the vertical stiffener is directly related to its area. Thus, to ensure the bearing capacity and ductility of the L-CFST column connection, a sufficient bearing capacity of the vertical stiffener is required.

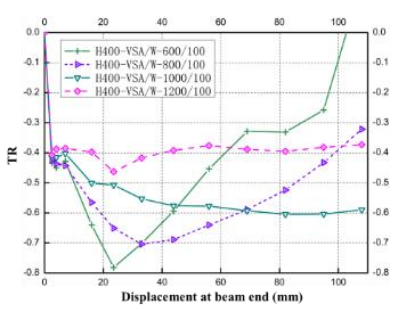

(a)

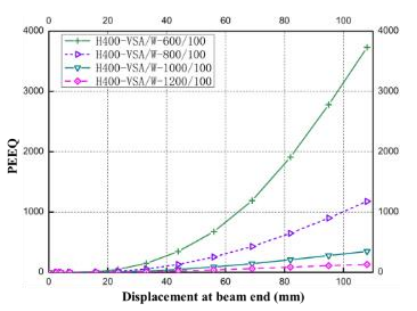

(b)

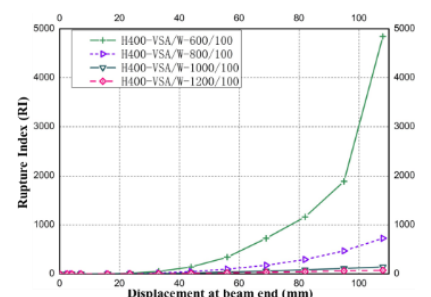

(c)

Fig. 15 TR, PEEQ, and RI at critical point (c) with beam end displacement for different vertical stiffener areas in the $\mathrm{H} 400$ series

To ensure the flexural capacity of the connection, the analytic models H400-VSA/W-1200/80， H400-VSA/W-1200/100， H400-VSA/W-1200/120 and H400-VSA/W-1200/150 with a unilateral vertical stiffener area of 1200 $\mathrm{mm}^{2}$ were used as the research objects; the width-to-thickness ratios were 5.3, 8.3, 12 and 37.5, respectively. Fig. 16 presents the variation trend of the TR, PEEQ and RI indices of these four analytic models at critical point $\mathrm{c}$ with the beam end displacement. With the increase in width-to-thickness ratio of the vertical stiffener, the TR index significantly decreased. For the analytic model
H400-VSA/W-1200/150, the minimum TR value was close to -0.6 , which indicates that a greater width-to-thickness ratio of the specimen corresponds to a more obvious degree of its stress concentration at characteristic point $\mathrm{c}$. Similarly, as shown in Fig. 16 (b), for the model H400-VSA/W-1200/80 with the width-to-thickness ratio of 5.3, PEEQ and RI were approximately $1 / 10$ and $1 / 8$ of those of the other analytic models. Its rupture risk at critical point $\mathrm{c}$ obviously decreased. In Fig. 17, when the width-to-thickness ratio was less than 10 , the RI value at the peak force state significantly decreased. When the widthto-thickness ratio was 5.3, the RI value was minimal. Thus, in the connection design, to ensure that the vertical stiffeners do not protrude beyond the wall, the width-to-thickness ratio of the vertical stiffener can be appropriately reduced to prevent the vertical stiffener from a sudden rupture at characteristic point $\mathrm{c}$.

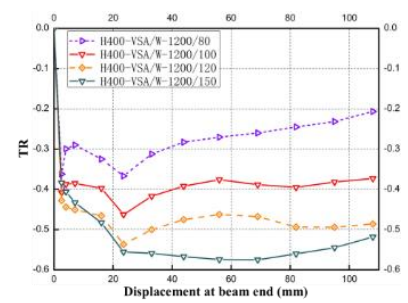

(a)

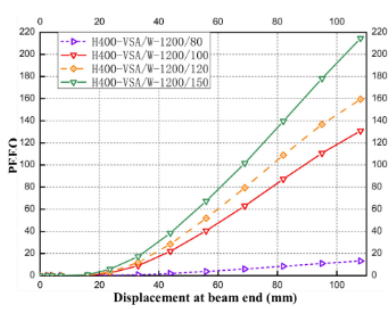

(b)

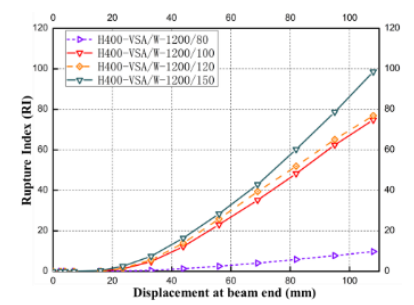

(c)

Fig. 16 TR, PEEQ, and RI at critical point $\mathrm{c}$ with beam end displacement for different vertical stiffener width-to-thickness ratios in the $\mathrm{H} 400$ series

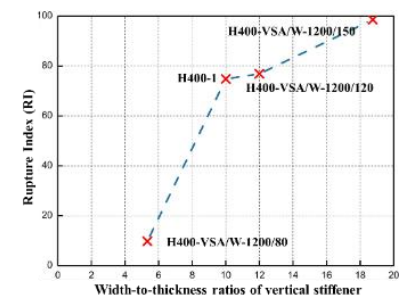

Fig. 17 RI at critical point $\mathrm{c}$ with vertical stiffener width-to-thickness ratios in the $\mathrm{H} 400$ series at the peak force state

\subsection{Flexural capacity calculation method}

Fig. 18 shows a typical span in the design of the L-CFST column frame system. The steel beam was under the uniformly distributed load $\mathrm{q}$ and concentrated load p. According to existing research [29], for the flangereinforced connection, the location easily formed a plastic hinge at Position 1 located at $1 / 4 \mathrm{H}_{\mathrm{B}}$ from the end of the vertical stiffener. Position 2 checked the flexural capacity of the panel zone considering the twisting effect of the L-CFST column and fillet weld strength between the vertical stiffener and the beam flange connecting plate.

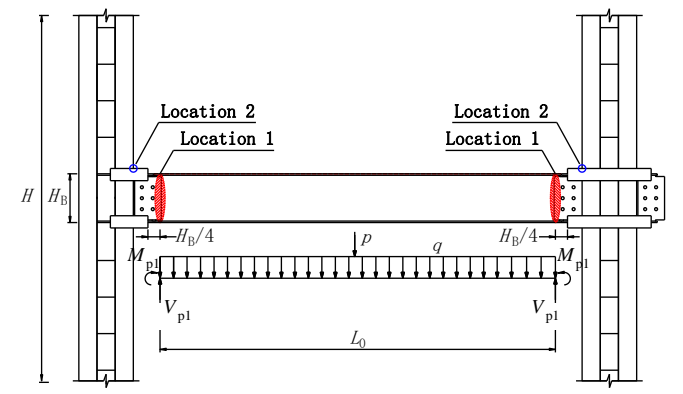

Fig. 18 Anti-seismic analysis model of the connection to the L-CFST column

The yield flexural capacity of the vertical stiffener connection to the 
rectangular CFST column based on the theory of yield line can be calculated using Eq. (4), [30]

$M_{Y}=\beta\left(2 h_{v s} t_{v s} f_{v s y}+t_{m c}\left(t_{b f c p}+\sqrt{D_{0} t_{c}}\right) f_{m c y}+4 D_{0} m_{p} \frac{1}{\sqrt{D_{0} t_{c}}}\right) \times\left(H_{B}-t_{b f}\right)$

where $M_{Y}$ is the yield flexural capacities of the panel zone; hvs is the width of the vertical stiffener; $t_{v s}$ is the thickness of the vertical stiffener; fvsy is the yield strength of the vertical stiffener; $t_{m c}$ is the thickness of the mono steel tube connected with the steel beam; $t_{d}$ is the thickness of the steel beam connecting plate; $\mathrm{D}_{0}$ is the width of the weld between the steel beam connecting plate and the beam flange; $t_{b f}$ is the thickness of the steel beam flange; $m_{p}=f_{y} \cdot t_{c}{ }^{2} / 4$ is the yield bending moment of the column wall per unit length; $\mathrm{H}_{\mathrm{B}}$ is the height of the steel beam; $\beta$ is the adjustment coefficient based on the previous test results. The yield and ultimate bearing capacity are calculated to be 0.8 and 0.7 , respectively.

The torsional stress of the vertical stiffener can be calculated using Eq. (5),

$\tau_{T}=\frac{T}{W_{t}}$

where $\mathrm{T}$ is the torque of the cross section at the column flange, and $\mathrm{W}_{\mathrm{t}}$ is the torsion resistant cross-sectional modulus of the L-CFST column in Eqs. (6) and (7), respectively,

$T=F_{L-C} \times e=\frac{M_{p b}}{H_{B}-t_{b f}} \times e$

$W_{\mathrm{t}}=\frac{I_{\mathrm{p}}}{\rho_{\max }}$

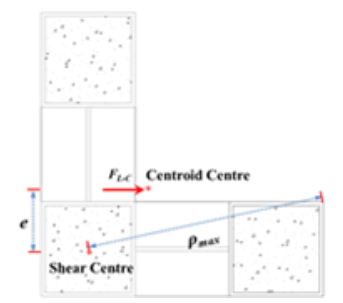

The specimens H400-0 and H400-1, whose panel zone failed in the experiment, are selected as examples to verify the above formulas. The comparison of the test results, existing methods and proposed theoretical formulas for the yield and ultimate flexural capacity of the connections is presented in Table 4.

Table 4 shows that the proposed predicted yield $\mathrm{M}_{\mathrm{PY}}$ and ultimate flexura capacity $\mathrm{M}_{\mathrm{PU}}$ are closer to the experimental results than the calculation method of DB/T29-186-2011. The standard deviations of the proposed formulas are also acceptable.

Fig. 19 A schematic diagram of shear stress calculation

Table 4

Comparison of the experimental and predictive values for the end plate connections

\begin{tabular}{|c|c|c|c|c|c|c|c|c|c|c|}
\hline \multirow[b]{2}{*}{ Specimen } & \multicolumn{2}{|c|}{ Test } & \multicolumn{4}{|c|}{ DB/T29-186-2011 } & \multicolumn{4}{|c|}{ Proposed formula } \\
\hline & $\begin{array}{c}\mathrm{M}_{\mathrm{TY}} \\
(\mathrm{kN} \cdot \mathrm{m})\end{array}$ & $\begin{array}{c}\mathrm{M}_{\mathrm{TU}} \\
(\mathrm{kN} \cdot \mathrm{m})\end{array}$ & $\begin{array}{c}\mathrm{M}_{\mathrm{Y}} \\
(\mathrm{kN} \cdot \mathrm{m})\end{array}$ & $\begin{array}{c}\mathrm{M}_{\mathrm{U}} \\
(\mathrm{kN} \cdot \mathrm{m})\end{array}$ & $\frac{M_{\mathrm{Y}}}{M_{\mathrm{TY}}}$ & $\frac{M_{\mathrm{U}}}{M_{\mathrm{TU}}}$ & $\begin{array}{c}\mathrm{M}_{\mathrm{PY}} \\
(\mathrm{kN} \cdot \mathrm{m})\end{array}$ & $\begin{array}{c}\mathrm{M}_{\mathrm{PU}} \\
(\mathrm{kN} \cdot \mathrm{m})\end{array}$ & $\frac{M_{\mathrm{FY}}}{M_{\mathrm{TY}}}$ & $\frac{M_{\mathrm{FU}}}{M_{\mathrm{TU}}}$ \\
\hline $\mathrm{H} 400-0$ & 231.4 & 301.3 & 185.1 & 214.2 & 0.80 & 0.71 & 191.3 & 299.5 & 0.83 & 0.99 \\
\hline H400-1 & 303.5 & 435.6 & 306.0 & 377.7 & 1.00 & 0.87 & 304.2 & 440.6 & 1.0 & 1.01 \\
\hline Average & & & & & 0.90 & 0.79 & & & 0.92 & 1.0 \\
\hline Standard Deviation & & & & & 0.1 & 0.08 & & & 0.08 & 0.01 \\
\hline
\end{tabular}

\subsection{Design Example}

In the L-CFST column frame system, the design steps of the flexural capacity of the vertical stiffener connection are shown in Table 5. The used parameters are related to Fig. 18 and Eqs. (4)-(10). The material strength is the design value. The vertical stiffener connection details are the following geometry and properties.
The H-shaped steel beam: $\mathrm{B}_{\mathrm{bf}}=150 \mathrm{~mm}, \mathrm{H}_{\mathrm{B}}=300 \mathrm{~mm}, \mathrm{t}_{\mathrm{bf}}=8 \mathrm{~mm}, \mathrm{t}_{\mathrm{w}}=6$ $\mathrm{mm} ; \mathrm{f}_{\mathrm{b}}=345 \mathrm{M}_{\mathrm{pa}} ; \mathrm{W}_{\mathrm{pb}}=471384 \mathrm{~mm}^{3}$; The beam flange connecting plate: $\mathrm{t}_{\mathrm{bfcp}}=$ $12 \mathrm{~mm}$; The steel tube of mono column: $B_{m c}=150 \mathrm{~mm}, \mathrm{t}_{\mathrm{mc}}=6 \mathrm{~mm}, \mathrm{f}_{\mathrm{mc}}=345 \mathrm{Mpa}$; The vertical steel plate: $B_{\mathrm{vsp}}=150 \mathrm{~mm}, \mathrm{t}_{\mathrm{vsp}}=6 \mathrm{~mm}$; The vertical stiffener: $\mathrm{h}_{\mathrm{vs}}=$ $100 \mathrm{~mm} ; \mathrm{h}_{\mathrm{vs}}=6 \mathrm{~mm}$; The torque: $\mathrm{T}=556.9 \times 99.35=55328 \mathrm{kN} \cdot \mathrm{mm}$; The torsion resistant cross sectional modulus of the L-CFST column: $\mathrm{W}_{\mathrm{t}}=11366800.2 \mathrm{~mm}^{3}$; The strength of fillet weld: $f_{v}{ }^{w}=200 \mathrm{Mpa}$. 
Table 5

Summary of the vertical stiffener design

\begin{tabular}{|c|c|}
\hline Design step & Calculations \\
\hline $\begin{array}{l}\text { 1- Determining the thickness of beam flange con- } \\
\text { necting plate }\end{array}$ & $\mathrm{t}_{\mathrm{bfcp}}=\mathrm{t}_{\mathrm{bf}}+4 \mathrm{~mm}=12 \mathrm{~mm}$ \\
\hline 2- Beam design moment & $\mathrm{M}_{\mathrm{p}}=\mathrm{W}_{\mathrm{pb}} \times \mathrm{fb}_{\mathrm{b}}=471384 \times 345=162627 \mathrm{kN} \cdot \mathrm{mm}$ \\
\hline 3- Axial force in the beam flange & $\mathrm{F}_{\mathrm{bf}}=\mathrm{M}_{\mathrm{p}} /\left(\mathrm{H}_{\mathrm{B}}-\mathrm{t}_{\mathrm{bf}}\right)=162627 /(300-8)=556.9 \mathrm{kN}$ \\
\hline \multirow{3}{*}{ 4- Controlling the dimension of vertical stiffener } & $h_{v s} t_{v s}=\frac{F_{b f}-t_{m c}\left(t_{b f c p}+\sqrt{D_{0} t_{m c}}\right) f_{m c}-4 D_{0} m_{p} \frac{1}{\sqrt{D_{0} t_{m c}}}}{2\left(f_{v s}-\frac{T}{W_{t}}\right)}$ \\
\hline & $556900-6 \times(12+\sqrt{138 \times 6}) \times 345-4 \times 138 \times \frac{1}{4} \times 6^{2} \times 345 \times \frac{1}{\sqrt{138 \times 6}}$ \\
\hline & $2 \times\left(345-\frac{55328000}{11366800.2}\right)$ \\
\hline \multicolumn{2}{|r|}{$\approx 600 \mathrm{~mm}^{2}$} \\
\hline $\begin{array}{l}\text { 5- Controlling the double fillet weld between the } \\
\text { beam flange connecting plate and the vertical } \\
\text { stiffener }\end{array}$ & $L_{1}=\frac{h_{v s} t_{v s} f_{v s}}{2 f_{v}^{\mathrm{w}} a_{e}}+2 h_{f}=\frac{100 \times 6 \times 345}{2 \times 200 \times 0.7 \times 7}+2 \times 7 \approx 120 \mathrm{~mm}$ \\
\hline $\begin{array}{l}\text { 6- Controlling the sides fillet welds between ver- } \\
\text { tical stiffenerand column flange }\end{array}$ & $L_{m c}=\frac{h_{v s} t_{v s} f_{v s}}{f_{v}^{w} a_{e}}+2 h_{v s}=\frac{100 \times 6 \times 345}{200 \times 0.7 \times 7}+2 \times 7=119.6 \mathrm{~mm}<\mathrm{B}_{m c}-2 t_{m c}=138 \mathrm{~mm}$ \\
\hline 7- Determining the section of vertical stiffener & $\begin{array}{c}\text { The cross section of } 60 \mathrm{~mm} \times 10 \mathrm{~mm} \text { can be selected, whose } h_{v s} / t_{v s} \text { is } 6 . \text { According to Fig. } 17 \text {, the section satisfies the design re- } \\
\text { quirements. }\end{array}$ \\
\hline
\end{tabular}

\section{Conclusion}

In this paper, the parameterized finite element optimization analysis was carried out in two series of connection models according to the test results. Comparisons were made in the skeleton curve, Von Mises stress distribution and rupture index at the critical position. Then, the flexural capacity of the LCFST column considering the twist and the tensile force from the fillet welds between the vertical stiffener and beam flange connecting plate was given. The main conclusions as follows:

(1) Comparison among the models in the $\mathrm{H} 300$ series, the construction measure of thickening the beam flange connecting plate had obvious advantages over other optimization methods in the connection bearing capacity, plastic hinge formation and rupture risk at the critical position. When the beam flange connecting plate was thickened by $4 \mathrm{~mm}$, the bearing capacity no longer increased obviously, and the rupture index of the critical position reduced to the acceptable scope. Therefore, it was most economic and reasonable to adopt the construction measure of thickening the beam flange connecting plate by $4 \mathrm{~mm}$ to improve the seismic performance of the connection.

(2) It could be obtained from the comparison of the analytic models in the $\mathrm{H} 400$ series that the bearing capacity of the connection increased with the area of the vertical stiffener to a certain extent, but when the bending resistant bearing capacity of the connection exceeded the plastic flexural capacity of the entire plastic cross section of the steel beam, the increase of the vertical stiffener area contributed little to the bearing capacity of the connection. Meanwhile, when the vertical stiffener area was the same, with the increase of the width-tothickness ratio of the vertical stiffener, the rupture risk of the critical position of the vertical stiffener increased. Therefore, in the case of meeting the flexural capacity of the panel zone and the maximum thickness difference in the fillet weld connection between the steel tube and the vertical stiffener, the width-tothickness ratio of the vertical stiffener should be small to avoid the sudden rupture of the vertical stiffener.

(3) In a comparison of experimental results, the results of the proposed calculation methods exhibited excellent consistency with the experimental results for both the yield and ultimate flexural capacity. For the convenience of engineering application, a design example is given which adopting the experimental and numerical results in this paper.

\section{Acknowledgement}

This work was sponsored by the National Key Research and Development Program of China (Grant No. 2017YFC0703802) and the Key Project of Hebei Natural Science Foundation, China (Grant No. E2017202278).

\section{References}

[1] JGJ 149-2017. Technical specification for concrete structures with specially shaped columns. Ministry of Housing and Urban-Rural Development of the People's Republic of China, China, 2017. (in Chinese)

[2] Yu F., He S. and Niu D., "Study on unified bearing capacity of rectangular concrete-filled steel tubular column subjected to axial compression", Advanced Steel Construction, 8(1), 95$111,2012$.

[3] Hu J.W., Park J. and Leon R.T., "Advanced analysis and performance based evaluation of concrete filled tube (CFT) columns", Advanced Steel Construction, 6(4), 1019-1033, 2010.

[4] Wang H.Y. and Zha X.X., "Axial strength of CFST columns considering concrete age", Advanced Steel Construction, 139-150, 2(10), 2014.

[5] Guler S., Çopur A. and Aydogan M.A., "A comparative study on square and circular high strength concrete-filled steel tube columns", Advanced Steel Construction, 10(2), 234-247, 2014.

[6] Li G.C., Di C.Y., Tian L. and Fang C., "Nonlinear finite element analysis on long columns of high-strength concrete-filled square steel tube with inner CFRP circular tube under axial load", Advanced Steel Construction, 9(2), 124-138, 2013.

[7] Chen Z.Y. and Shen Z.Y., "Behavior of L-shaped concrete-filled steel stub columns under axial loading: Experiment”, Advanced Steel Construction, 6(2), 688-697, 2010.

[8] Zhang W., Chen Z.H., Xiong Q.Q. and Zhou T., "Experimental seismic behavior of vertical stiffener connections to L-CFST columns", Steel and composite structure, 26(6), 793-808, 2018 .

[9] Zhou T., Xu M.Y., Chen Z.H., Wang X.D. and Wang Y.W., "Eccentric loading behavior of 1-shaped columns composed of concrete-filled steel tubes", 12(3), 227-244, 2016.

[10] Lee S.H., Yang I.S. and Choi S.M., "Structural characteristics of welded built-up square CFT column-to-beam connections with external diaphragms", Steel and Composite Structures, 10(3), 261-279, 2010

[11] Qin Y., Chen Z.H., Wang X.D. and Zhou T., "Seismic behavior of through-diaphragm connections between CFRT columns and steel beams-experimental study", Advanced Steel Construction, 10(3), 351-371, 2014.

[12] Chen Z.H., Qin Y. and Wang X.D., "Development of connections to concrete-filled rectangular tubular columns", Advanced Steel Construction, 11(4), 408-426, 2015.

[13] Kang L., Leon R.T. and Lu X., "Shear strength analyses of internal diaphragm connections to CFT columns", Steel and Composite Structures, 18(5), 1083-1101,2015.

[14] Guo Y. and Yao X., "Seismic performance and design of reduced steel beam section with concrete filled square tubular column", Advanced Steel Construction, 9(3), 173-189, 2013.

[15] Kimura J., Choi S., Matsui C. and Chung J., "Structural characteristics of H-shaped beam-tosquare tube column connection with vertical stiffeners", International Journal of Steel Structures, 5(2), 109-117, 2005.

[16] Shin K.J., Kim Y.J. and Oh Y.S., "Seismic behaviour of composite concrete-filled tube column-to-beam moment connections", Journal of Constructional Steel Research, 64(1), 118$127,2008$.

[17] Kang C.H., Kim Y.J., Shin K.J. and Oh Y.S., "Experimental investigation of composite moment connections with external stiffeners", Advances in Structural Engineering, 16(10), 1683-1700, 2013

[18] Kang C.H., Shin K.J., Oh Y.S. and Moon T.S., "Hysteresis behavior of CFT column to Hbeam connections with external T-stiffeners and penetrated elements", Engineering Structures, 23(9), 1194-1201, 2001.

[19] Xue J.Y., Chen X., Zhou P., Ge H.P. and Zeng F.S., "Shear capacity of joints between concrete-filled square steel tubular special-shaped columns and steel beams", Journal of Building Structures, 33(8), 51-57, 2012. (in Chinese)

[20] Xu C.X., Wan B. and Zhang J.C., "Experimental research on seismic behavior of interior joints in the composite frame consisting of CFST crisscross section columns and steel beams", Journal of Building Structures, 42(3), 80-83, 2012. (in Chinese)

[21] Ma R.Q., Ban H.Y., Zhao Y.Z., Wang Y.Q., Li Q. and Liu M., "Experimental study on seismic behavior of steel beam to wide-flange specially-shaped composite column connections", Journal of Building Structures, 38(6), 105-111, 2017. (in Chinese) 
[22] Ghobadi M.S., Mazroi A. and Ghassemieh M., "Cyclic response characteristics of retrofitted moment resisting connections", Journal of Constructional Steel Research, 65(3), 586-598, 2009.

[23] Ghobadi M.S., Ghassemieh M., Mazroi A. and Abolmaali A., "Seismic performance of ductile welded connections using T-stiffener", Journal of Constructional Steel Research, 65(4), 766-775, 2009.

[24] Hancock J.W. and Mackenzie, A.C., "On the mechanisms of ductile failure in high strength steels subjected to multi-axial stress states", Journal of the Mechanics and Physics of Solids, 24(2), 147-69, 1976

[25] Mao C., Ricles J.M., Lu L.W. and Fisher J.W., "Effect of local details on ductility of welded moment connections", Journal of Structural Engineering, 127(9), 1036-1044, 2001.

[26] Atashzaban A., Hajirasouliha I., Jazany R.A. and Izadinia M., "Optimum drilled flange moment resisting connections for seismic regions". Journal of Constructional Steel Research, $112,325-338,2015$

[27] Roudsari M.T., Abdollahi F., Salimi H., Azizi S. and Khosravi A.R., "The effect of stiffener on behavior of reduced beam section connections in steel moment-resisting frames", International Journal of Steel Structures, 15(4), 827-834, 2015.

[28] El-Tawil S., Mikesell T. Vidarsson E. and Kunnath S. "Strength and ductility of FR welded bolted connections", Report No. SAC/BD-98/01, Sacramento, CA: SAC Joint Venture, 1998.

[29] Wang Y., Feng S. and Wang Y.T., "Experimental study on hysteretic behavior for rigidreinforced connections", China Civil Engineering Journal, 44(5), 57-68, 2011. (in Chinese)

[30] DB/T29-186-2011. Technical specification for connection in CRFT structure of Tianjin, Tianjin Urban \& Rural Construction Commission, Tianjin, China, 2011.

[31] Nie J.G., Qin K. and Cai C.S.,"Seismic behavior of composite connections - flexural capacity analysis", Journal of Constructional Steel Research, 65(5), 1112-1120, 2009.

[32]Dai G.X. "Study and Evaluation Reliability of Steel Structural Buildings", Chongqing University, 2004 